\title{
The harsh microenvironment in infarcted heart accelerates transplanted bone marrow mesenchymal stem cells injury: the role of injured cardiomyocytes-derived exosomes
}

\author{
Ming Hu', Guixian Guo', Qiang Huang ${ }^{1}$, Chuanfang Cheng ${ }^{1}$, Ruqin $\mathrm{Xu}^{1}$, Aiqun Li ${ }^{1}$, Ningning Liu ${ }^{1}$ and Shiming Liu ${ }^{1}$
}

\begin{abstract}
Stem cell therapy can be used to repair and regenerate damaged hearts tissue; nevertheless, the low survival rate of transplanted cells limits their therapeutic efficacy. Recently, it has been proposed that exosomes regulate multiple cellular processes by mediating cell survival and communication among cells. The following study investigates whether injured cardiomyocytes-derived exosomes (cardiac exosomes) affect the survival of transplanted bone marrow mesenchymal stem cells (BMSCs) in infarcted heart. To mimic the harsh microenvironment in infarcted heart that the cardiomyocytes or transplanted BMSCs encounter in vivo, cardiomyocytes conditioned medium and cardiac exosomes collected from $\mathrm{H}_{2} \mathrm{O}_{2}$-treated cardiomyocytes culture medium were cultured with BMSCs under oxidative stress in vitro. Cardiomyocytes conditioned medium and cardiac exosomes significantly accelerated the injury of BMSCs induced by $\mathrm{H}_{2} \mathrm{O}_{2}$; increased cleaved caspase-3/caspase-3 and apoptotic percentage, and decreased the ratio of $\mathrm{BCl}-2 / \mathrm{Bax}$ and cell viability in those cells. Next, we explored the role of cardiac exosomes in the survival of transplanted BMSCs in vivo by constructing a Rab27a knockout (KO) mice model by a transcription activator-like effector nuclease (TALEN) genome-editing technique; Rab27a is a family of GTPases, which has critical role in secretion of exosomes. Male mouse GFP-modified BMSCs were implanted into the viable myocardium bordering the infarction in Rab27a KO and wild-type female mice. The obtained results showed that the transplanted BMSCs survival in infarcted heart was increased in Rab27a KO mice by the higher level of Y-chromosome Sry DNA, GFP mRNA, and the GFP fluorescence signal intensity. To sum up, these findings revealed that the injured cardiomyocytes-derived exosomes accelerate transplanted BMSCs injury in infarcted heart, thus highlighting a new mechanism underlying the survival of transplanted cells after myocardial infarction.
\end{abstract}

\section{Introduction}

Stem cell-based therapy for myocardial infarction (MI) has received unprecedented attention over the last

\footnotetext{
Correspondence: Ningning Liu (Inn425@163.com) or

Shiming Liu (liushiming@gzhmu.edu.cn)

'Guangzhou Institute of Cardiovascular Disease, the Second Affiliated Hospital

of Guangzhou Medical University, Guangzhou, 510260 Guangdong, China

Edited by A. Stephanou
}

decades $^{1,2}$. Bone marrow mesenchymal stem cells (BMSCs), because of their unique properties for easily obtain, multilineage potential, high proliferation, and immune privilege, have become an attractive cell for transplantation therapy to $\mathrm{MI}^{3,4}$. Nevertheless, the poor cell survival in the harsh ischemic heart microenvironment limits their therapeutic efficacy, thus urging the identification of new and effective approaches, as well as 
exploration of mechanisms underlying BMSCs in $\mathrm{MI}^{5}$. So far, several approaches have been proposed to improve the survival of engrafted cells, including preconditioning, genetic modification, and improving host tissue environment ${ }^{6-10}$. Many cell types interact in a high coordinated manner to control heart integrity and homeostasis, including cardiomyocytes (CMs), myofibroblasts, immune cells, cardiac-derived stem cells, and endothelial cytes ${ }^{11,12}$. Recently, exosomes have shown to regulate multiple processes, including cell survival, angiogenesis, and immune responses, by mediating the communication among cells/organs ${ }^{13}$. Although CMs do not act as typical secretory cells, exosomes can be secreted from these cells in an inducible manner. Together with trophic factors and signaling molecules, the exosomes secreted from CMs have been proposed to be critical for myocardium by mediating intercellular contacts ${ }^{14}$. It remains largely unknown whether the injured CMs-derived exosomes (cardiac exosomes) have an ability to affect the survival of transplanted BMSCs after MI.

Exosomes are a subfamily of extracellular vesicles (EVs) that correspond to the internal vesicles present in multivescular endosomes (MVEs), and their size usually ranges from 40 to $200 \mathrm{~nm}^{12}$. Upon MVEs fusing with plasma membrane, exosomes are constitutively released into the extracellular environment. Rab proteins, a family of GTPases, functionally participate in different steps of intracellular membrane trafficking, including endocytic and secretory processes, as well as exosome production or secretion ${ }^{15}$. Knockdown of Rab27b is suggested to redistribute the MVEs toward perinuclear region, while late endosome and lysosome compartments get accumulated and enlarged in Rab27a genetic inhibition cells. This suggests that Rab27a is necessary for the docking and fusion of MVEs with the plasma membrane, and is also important in exosomes secretion ${ }^{16}$. In order to explore the role of cardiac exosomes in the survival of transplanted BMSCs in vivo, we constructed a Rab27a KO mice model following the implantation of GFP-modified BMSCs into the viable myocardium bordering the infarction in Rab27a KO female mice. Consequently, the survival of transplanted cells was assessed by the expression of Y-chromosome Sry DNA and GFP mRNA, as well as by detecting GFP fluorescence signal intensity. In this study, in vitro and in vivo assays were carried out to determine the effects of the cardiac exosomes on survival of transplanted BMSCs in infarcted heart.

\section{Results}

\section{Oxidative stress caused apoptosis of CMs and BMSCs}

To mimic the oxidative stress microenvironment after $\mathrm{MI}$ in vivo, the CMs and BMSCs were exposed to different concentrations of $\mathrm{H}_{2} \mathrm{O}_{2}$ for $24 \mathrm{~h}$. Cells were then harvested for protein collection and subjected to western blot analysis. The CMs apoptosis was positively correlated with $\mathrm{H}_{2} \mathrm{O}_{2}$ concentration, as showed by the elevated cleaved caspase-3/caspase-3 expression (Fig. 1a, b); Annexin V-FITC/PI assay showed that $\mathrm{H}_{2} \mathrm{O}_{2}$ dose dependently induced CMs cell apoptosis ratio by $19.9 \pm 1.6 \%, 24.6 \pm 0.5 \%$, and $30.8 \pm 6.7 \%$ compared to the control group $(7.4 \pm 3.5 \%)(p<0.05)$ (Fig. 1e, f). A serious damage of CMs was caused by $300 \mu \mathrm{M} \mathrm{H}_{2} \mathrm{O}_{2}$, therefore $100 \mu \mathrm{M}$ was selected as a stimulating concentration. Furthermore, by increasing the concentration of $\mathrm{H}_{2} \mathrm{O}_{2}$, a significant increase in cleaved caspase- 3 was observed in BMSCs (Fig. 1c, d); and BMSCs cell apoptosis ratio by $14.5 \pm 2.1 \%, 19.4 \pm 1.0 \%$, and $26.3 \pm 4.7 \%$, compared to the control group $(6.2 \pm 5.4 \%) \quad(p<0.05)$ (Figures 1g, h). Additionally, decreased BMSC cell viability was observed when treating cells with $300 \mu \mathrm{M}(88.9 \pm 4.0 \%), 500 \mu \mathrm{M}$ (69.8 $\pm 4.6 \%), 700 \mu \mathrm{M}(37.6 \pm 4.1 \%) \mathrm{H}_{2} \mathrm{O}_{2}$ compared with $\mathrm{NC}(p<0.05)$ (Fig. 1i). As the injury of $700 \mu \mathrm{M} \mathrm{H} \mathrm{H}_{2} \mathrm{O}_{2}$ showed to be too aggressive in promoting cell damage, the concentration of $500 \mu \mathrm{M}$ was selected to stimulate BMSCs.

\section{Cardiomyocytes conditioned medium accelerated apoptosis of BMSCs under oxidative stress}

In order to explore the mechanisms underlying the poor cell survival of implanted BMSCs in the ischemic heart environment, and whether CMs affect the survival of implanted BMSCs by paracrine action, we cultured BMSCs with CMs conditioned medium under $500 \mu \mathrm{M}$ $\mathrm{H}_{2} \mathrm{O}_{2}$ for $24 \mathrm{~h}$. The protein lysates were prepared and detected by western blot. Briefly, no statistical difference in cleaved caspase-3/caspase-3 expression was found between group Ctr-cdM and $\mathrm{Ctr}-\mathrm{H}_{2} \mathrm{O}_{2}-\mathrm{cdM}$, whereas it significantly increased in group cdM compared to group Ctr-cdM and in group $\mathrm{H}_{2} \mathrm{O}_{2}$-cdM compared to group Ctr- $\mathrm{H}_{2} \mathrm{O}_{2}$-cdM (Fig. 2d, e). In addition, western blot revealed that group cdM and group $\mathrm{H}_{2} \mathrm{O}_{2}$-cdM exhibited a significantly decreased ratio of $\mathrm{Bcl}-2 / \mathrm{Bax}$ compared to control group (Figure 2f). Moreover, cell viability was greatly decreased in group $\mathrm{cdM}(62.9 \pm 1.6)$ compared with group Ctr-cdM $(79.3 \pm 5.0)$ and in group $\mathrm{H}_{2} \mathrm{O}_{2}$-cdM $(54.7 \pm 2.1)$ relative to group $\mathrm{Ctr}-\mathrm{H}_{2} \mathrm{O}_{2}$-cdM $(75.2 \pm 9.6)$ upon treatment with $500 \mu \mathrm{M} \mathrm{H}_{2} \mathrm{O}_{2}$ for $24 \mathrm{~h}(p<0.05)$ (Figure 2h). Meanwhile, protein expression changed after culturing BMSCs with CMs conditioned medium in normal culture (without $500 \mu \mathrm{M} \mathrm{H}_{2} \mathrm{O}_{2}$ ) for $24 \mathrm{~h}$ in vitro; increased expression in cleaved caspase- $3 /$ caspase- 3 and decreased expression in the ratio of $\mathrm{Bcl}-2 / \mathrm{Bax}$ were found in group cdM relative to group Ctr-cdM and the same changes were found in group $\mathrm{H}_{2} \mathrm{O}_{2}$-cdM compared to group Ctr- $\mathrm{H}_{2} \mathrm{O}_{2}$-cdM (Fig. 2a-c). In addition, decreased cell viability was observed in cdM $(81.7 \pm 4.6 \%)$ compared to $\mathrm{H}_{2} \mathrm{O}_{2}$-cdM $\quad(70.5 \pm 4.7 \%) \quad(p<0.05) \quad$ (Figure $2 \mathrm{~g}$ ). Also, a more serious cell injury was caused by $\mathrm{H}_{2} \mathrm{O}_{2}$-cdM 

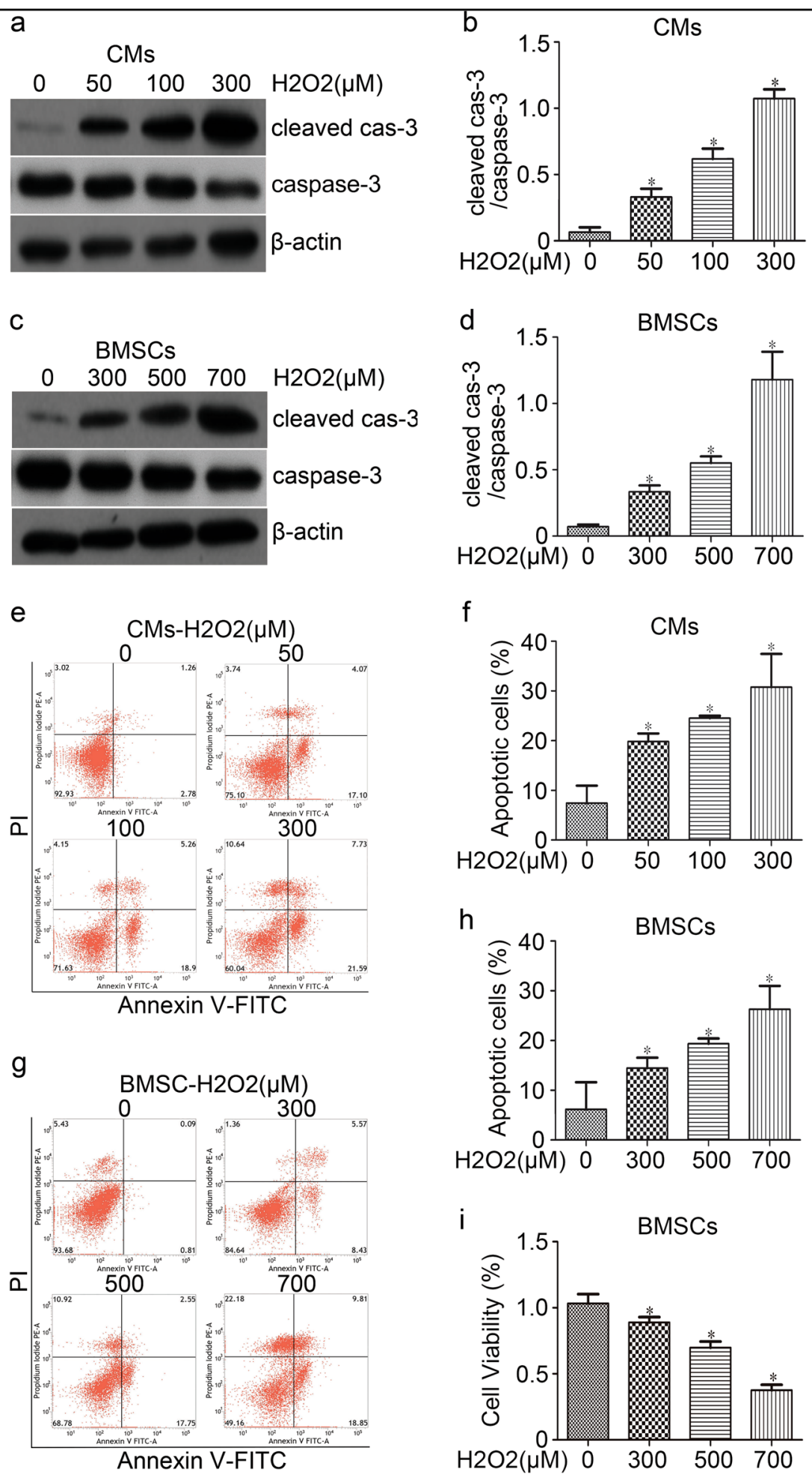

Fig. 1 Oxidative stress injury on CMs and BMSCs in vitro. $\mathrm{H}_{2} \mathrm{O}_{2}$ dose dependently induced apoptosis in CMs (a) or BMSCs (c) $24 \mathrm{~h}$ posttreatment. Protein lysates were subject to western blot analysis using antibodies as mentioned above. $\beta$-actin was employed as a loading control, and quantitative data of cleaved caspase 3 band densities were shown (b and $\mathbf{d})$. CMs (e) and BMSCs (g) cell apoptosis were assayed using Annexin V-FITC/PI dual staining by flow cytometry; representative flow images were shown. The percentages of apoptotic CMs and BMSCs cells were summarized as ( $\mathbf{f}$ and $\mathbf{h}$ ). $\mathbf{i}$ The BMSCs cell viability after treatment with different concentrations of $\mathrm{H}_{2} \mathrm{O}_{2}$ was detected by $C C K-8$ assay. ${ }^{*} p<0.05$ versus control group. All values were expressed as mean $\pm \mathrm{SD}, n=3$ for each group 


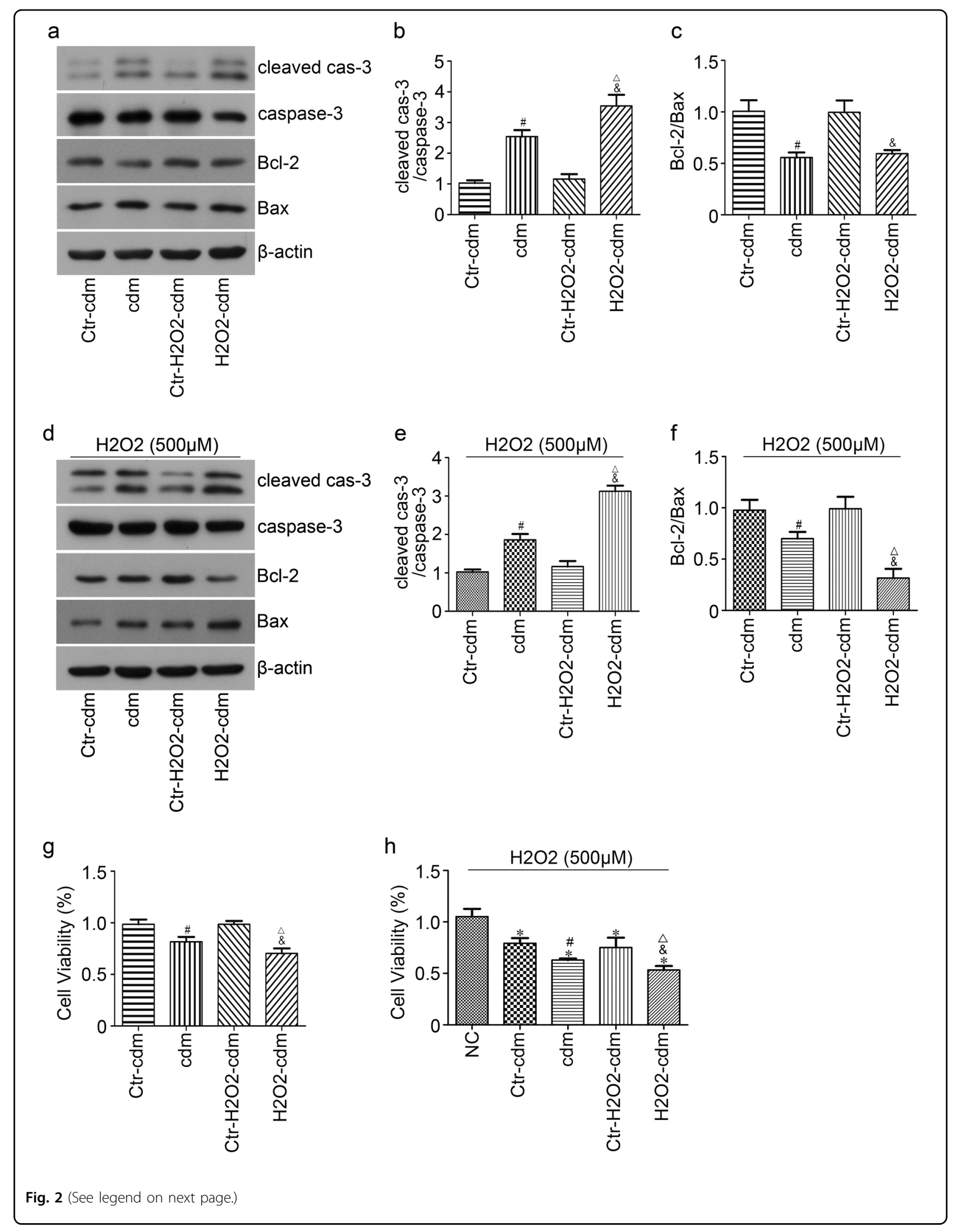


(see figure on previous page)

Fig. 2 Effects of cardiomyocytes conditioned medium on apoptosis of BMSCs under oxidative stress. a BMSCS were lysated for detecting cleaved caspase-3, caspase-3, Bcl-2, Bax after being cultured with cardiomyocytes conditioned medium and treated without (a) or with (d) $500 \mu \mathrm{M}$ $\mathrm{H}_{2} \mathrm{O}_{2}$ for $24 \mathrm{~h}$ by western blot. Quantitative data of cleaved caspase-3/caspase-3 (b and $\mathbf{e}$ ) and Bcl-2/Bax ratio (c and $\mathbf{f}$ ) were shown, respectively. The cell viability of BMSCs after being cultured with cardiomyocytes conditioned medium and treated without (g) or with (h) $500 \mu \mathrm{M} \mathrm{H} \mathrm{H}_{2} \mathrm{O}_{2}$ for $24 \mathrm{~h}$ was detected by CCK8 assay. NC BMSCs cells with DMEM containing 10\% FBS, cdM serum-free DMEM for culturing CMs for 24 h; $\mathrm{H}_{2} \mathrm{O}_{2}$-cdM serum-free DMEM, and $100 \mu \mathrm{M} \mathrm{H}_{2} \mathrm{O}_{2}$ used to treat CMs for $24 \mathrm{~h}$; Ctr-cdM (without CMs) and $\mathrm{Ctr}-\mathrm{H}_{2} \mathrm{O}_{2}-\mathrm{CdM}$ (without CMs) served as control of cdM and $\mathrm{H}_{2} \mathrm{O}_{2}-\mathrm{cdM}$, respectively. ${ }^{*} p<0.05$ versus NC, ${ }^{*} p<0.05$ versus $\mathrm{Ctr-cdM},{ }^{\&} p<0.05$ versus $\mathrm{Ctr}_{2} \mathrm{H}_{2} \mathrm{O}_{2}-\mathrm{cdM}, \triangle_{p}<0.05$ versus cdM. All values were expressed as mean $\pm S D, n=3$ for each group
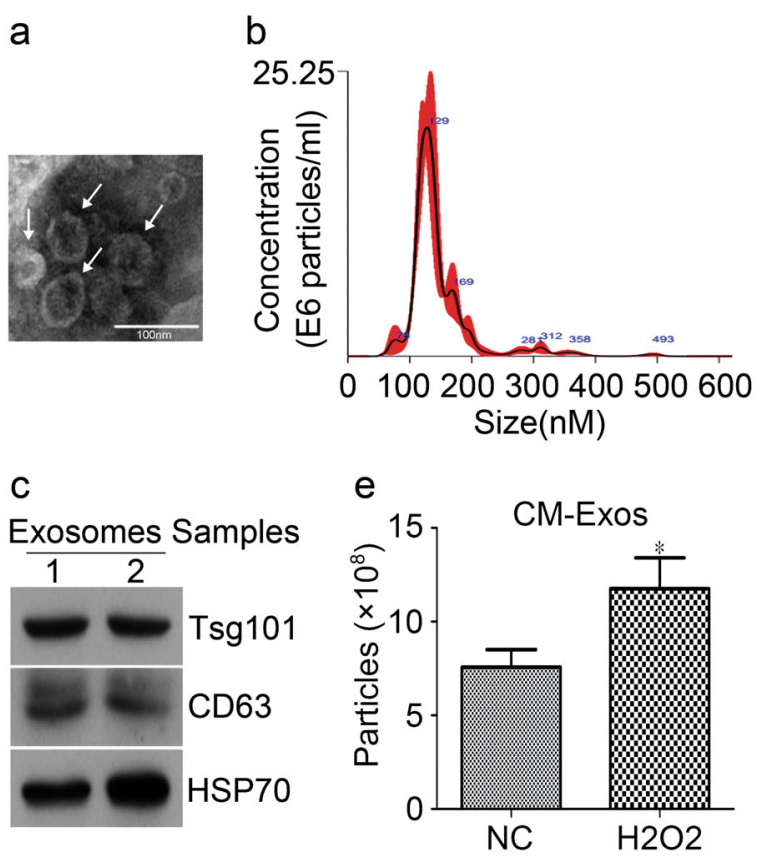

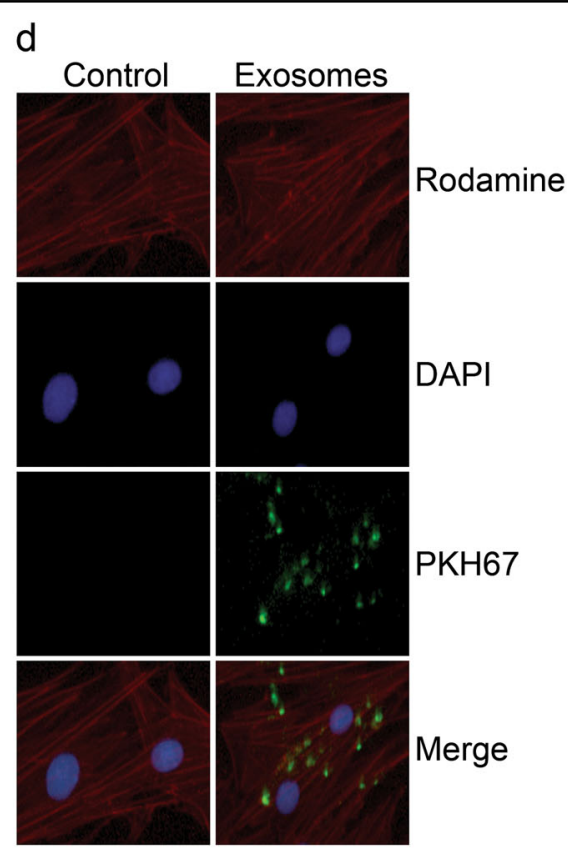

Fig. 3 Characteristics of cardiac exosomes. a The size and morphology of exosomes were confirmed by transmission electron microscopy (TEM). The arrows indicated the typical exosomes. Scale bar, $100 \mathrm{~nm}$. b The exosome size was measured using nanoparticle tracking analysis (NTA). The size of the exosomes between 100 and $200 \mathrm{~nm}$, and the mode of these particles is $128.2 \mathrm{~nm}$ ( $n=3$ independent experiments). c Exosomal markers including CD63, Tsg101and Hsp70 were measured by western blot. d Uptake of cardiac exosomes by BMSCs. BMSCs were cultured with PKH67labeled cardiac exosomes or control medium for $24 \mathrm{~h}$ and stained with DAPI and rhodaminephalloidin, the images were recorded under an inverted fluorescence microscopy. e The exosome concentrations between conditioned medium from CMs mixed with or without $100 \mu \mathrm{M} \mathrm{H} \mathrm{H}_{2} \mathrm{O}_{2}$ for $24 \mathrm{~h}$ were recorded by NTA. * $p<0.05$ versus NC. All values were expressed as mean $\pm S D, n=4$ for each group

compared to cdM. Accordingly, we explored what substances in the $\mathrm{H}_{2} \mathrm{O}_{2}$-cdM take effects.

\section{Identification of the cardiac exosomes}

To obtain cardiac exosomes, the $\mathrm{H}_{2} \mathrm{O}_{2}$-cdM was collected and differentially ultracentrifuged. The identification of the morphology and properties of isolated particles was performed as previously described ${ }^{17}$. First, TEM demonstrated that the particles exhibited rounded and double-membrane structures with a size of $\sim 50 \mathrm{~nm}$ (Fig. 3a). Secondly, nanoparticle tracking analysis (NTA) was performed to define the concentration and size distribution of the particles; a concentration of $1.07 \times 10^{9} \pm$ $1.43 \times 10^{8}$ particles per $\mathrm{ml}$ was found with diameter between 100 and $200 \mathrm{~nm}$, with the mode of $128.2 \mathrm{~nm}$
(Fig. 3b). Thirdly, Western blot was used to detect the exosomal protein markers CD63, HSP70, and Tsg101; all three markers were detected in the particles (Fig. 3c). Furthermore, the PKH67-labeled particles were cultured with BMSCs to confirm whether the secreted particles were incorporated into recipient BMSCs. Immunocytochemical analysis demonstrated that the PKH67-labeled particles (green fluorescence) were colocalized in the rhodaminephalloidin stained BMSCs (red fluorescence) after cultured for $24 \mathrm{~h}$ (Fig. 3d). Finally, the exosome concentrations between conditioned medium from CMs mixed with or without $100 \mu \mathrm{M} \mathrm{H} \mathrm{H}_{2} \mathrm{O}_{2}$ for $24 \mathrm{~h}$ were recorded by NTA. A total of $11.75 \times 10^{8} \pm 1.66 \times 10^{8}$ particles per ml was found in $\mathrm{H}_{2} \mathrm{O}_{2}$ group and $7.57 \times 10^{8}$ $\pm 0.94 \times 10^{8}$ in NC group (Fig. 3e). So, the above 

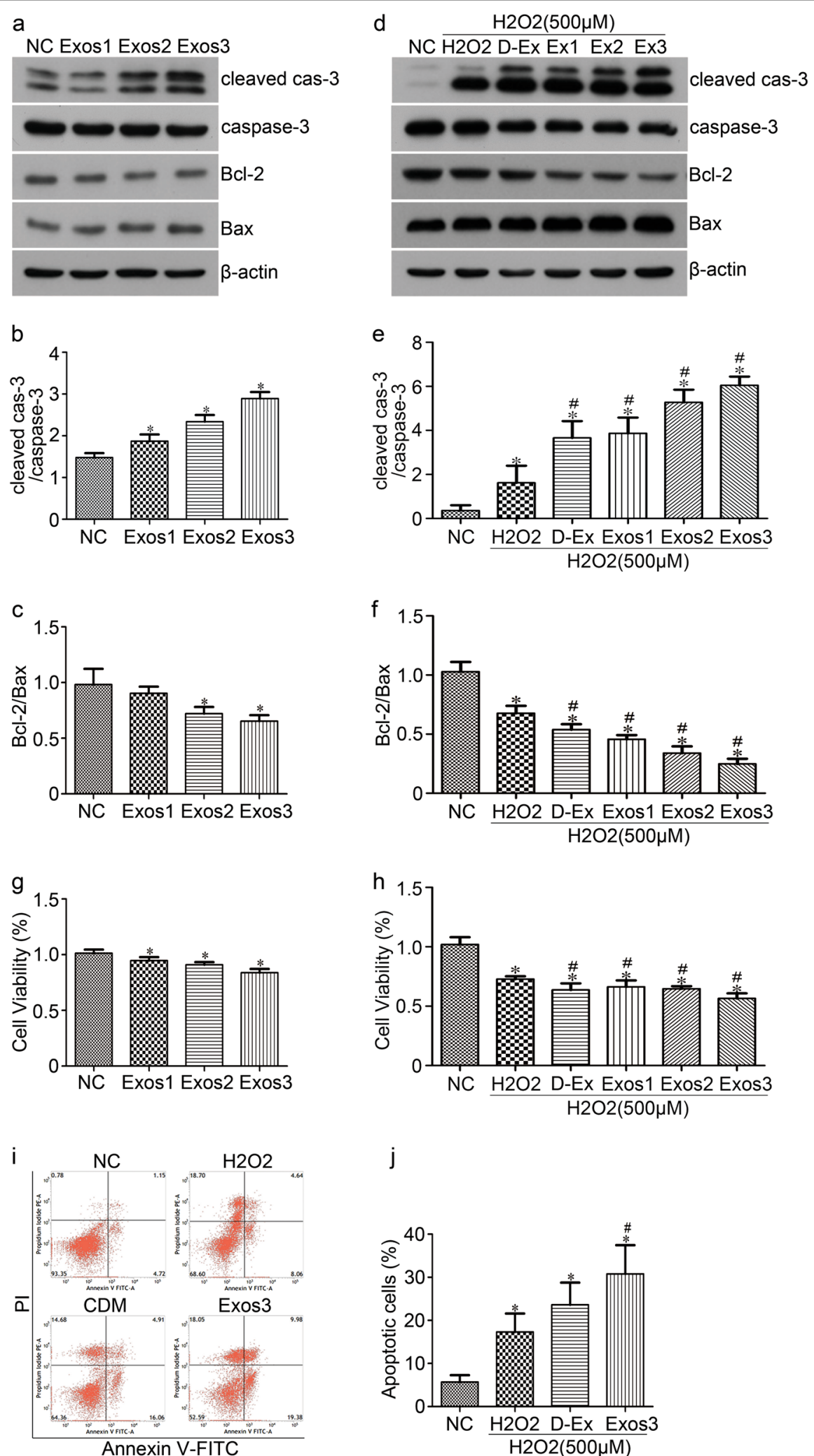

Fig. 4 (See legend on next page.) 
(see figure on previous page)

Fig. 4 The apoptotic effect of cardiac exosomes on BMSCs. a BMSCs were lysated for detecting cleaved caspase-3, caspase-3, BCl-2, Bax after 24 h culture with cardiac exosomes. Quantitative data of cleaved caspase-3/caspase-3 and Bcl-2/Bax ratio were shown (b and c). d BMSCs were lysated for detecting cleaved caspase-3, caspase-3, Bcl-2, Bax after $24 \mathrm{~h}$ pre-incubation with cardiac exosomes following treatment with serum-free DMEM and $500 \mathrm{\mu M} \mathrm{H}_{2} \mathrm{O}_{2}$ for additional $24 \mathrm{~h}$. Quantitative data of cleaved caspase-3/caspase-3 and Bcl-2/Bax ratio were shown (e and f). $\mathbf{g}$ The cell viability of BMSCs after cultured with cardiac exosomes for $24 \mathrm{~h}$ was detected by CCK8 assay. $\mathbf{h}$ The cell viability of BMSCs after $24 \mathrm{~h}$ pre-incubation with cardiac exosomes and then treated with serum-free DMEM and $500 \mu \mathrm{M} \mathrm{H}_{2} \mathrm{O}_{2}$ for additional $24 \mathrm{~h}$. i BMSCs cell apoptosis was assayed with Annexin V-FITC /PI dual staining by flow cytometry, representative flow images were shown. $\mathbf{j}$ The percentage of apoptotic BMSCs cells was summarized. NC BMSCs cells with DMEM containing $10 \%$ exosomes-depleted FBS, $\mathrm{H}_{2} \mathrm{O}_{2}$ BMSCs cells with $500 \mu \mathrm{M} \mathrm{H}_{2} \mathrm{O}_{2}$, D-Ex Exos-depleted $\mathrm{H}_{2} \mathrm{O}_{2}$-cdM, Exos Exosomes isolation from $\mathrm{H}_{2} \mathrm{O}_{2}$-cdM, Exos $11 \times 10^{9}$ particles $/ \mathrm{ml}$, Exos $22 \times 10^{9}$ particles $/ \mathrm{ml}$, Exos $34 \times 10^{9}$ particles $/ \mathrm{ml}$. ${ }^{*} p<0.05$ versus NC, ${ }^{\#} p<0.05$ versus $\mathrm{H}_{2} \mathrm{O}_{2}$. All values were expressed as mean $\pm \mathrm{SD}, n=3$ for each group
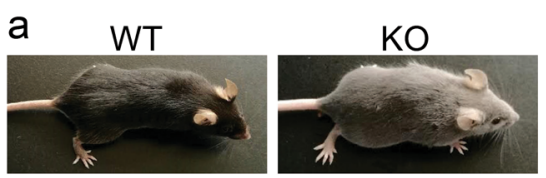

b
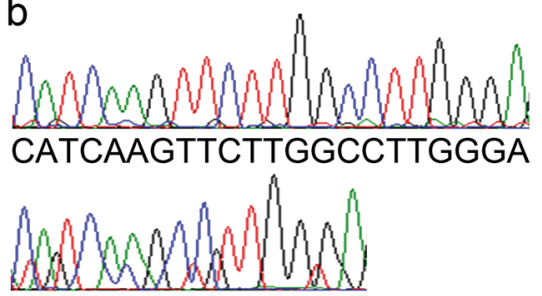

CATCAAGCCTTGGGA

C

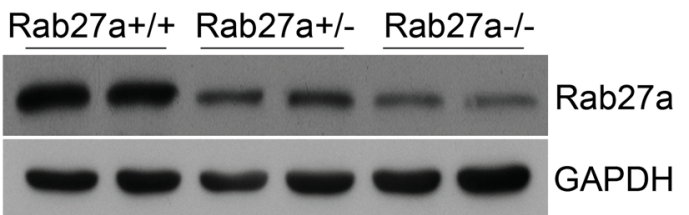

d

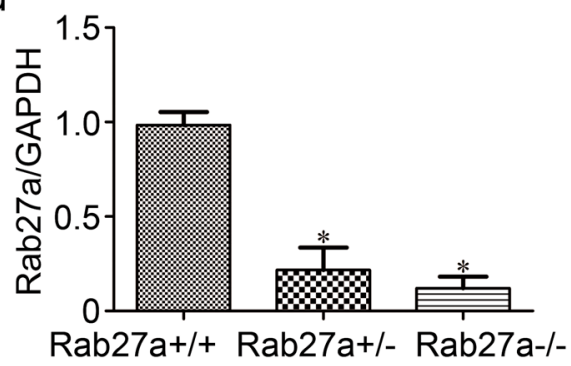

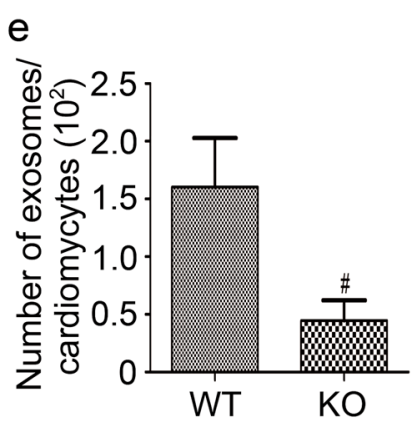

$f$
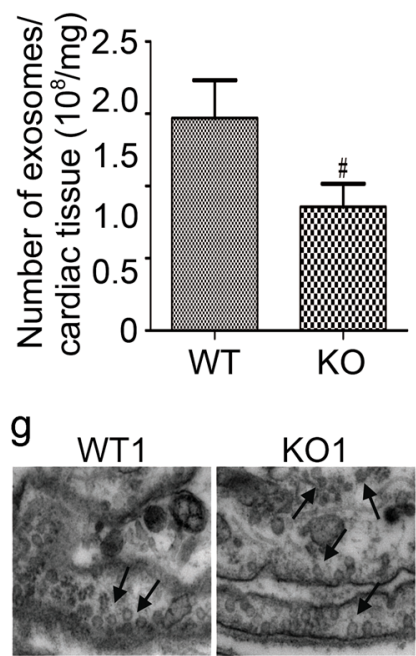

WT2

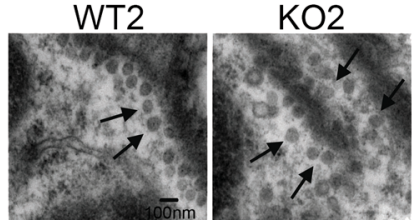

Fig. 5 The identification of Rab27a KO mouse and the ability of exosomes secretion. Construction of Rab27a KO mice model by TALEN genome-editing technologies; the coat color phenotype of wild type (WT) and Rab27a KO mice (a), and the diagram of TALEN target sites (b). c The level of Rab27a protein in cardiac tissues of WT and KO mice were analyzed by western blot; GAPDH was employed as a loading control. Quantitative data of Rab27a band densities were shown (d). e, f Quantitative data of exosomes released from cardiomyocytes and cardiac tissues. $\mathbf{g}$ TEM micrograph of exosomes in cardiac tissues, the arrows indicated the typical exosomes. Scale bar, $100 \mathrm{~nm} .{ }^{*} p<0.05$ versus Rab27a+/+. ${ }^{\#} p<0.05$ versus WT. All values expressed as mean $\pm \mathrm{SD}, n=4$ for each group 
a

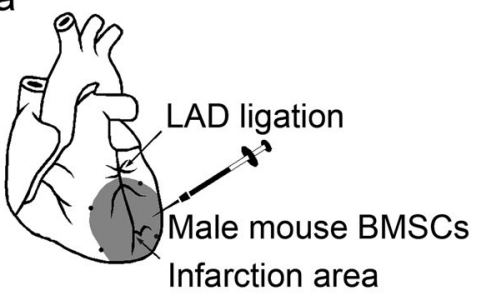

$\mathrm{C}$
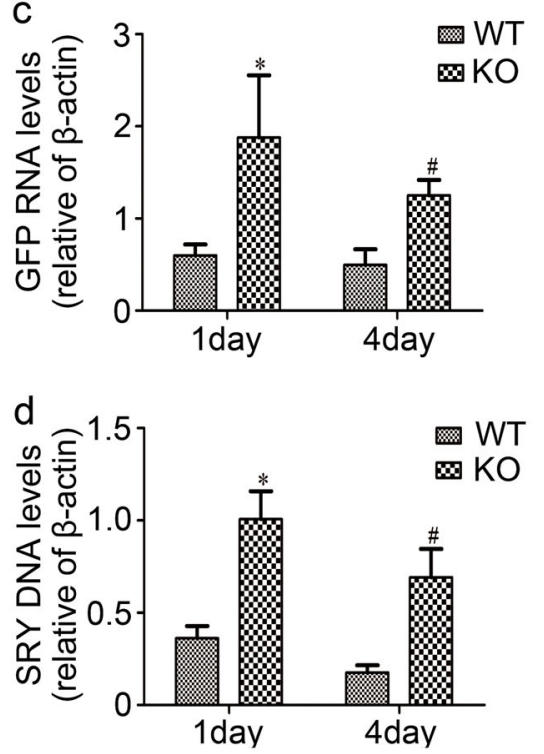

b

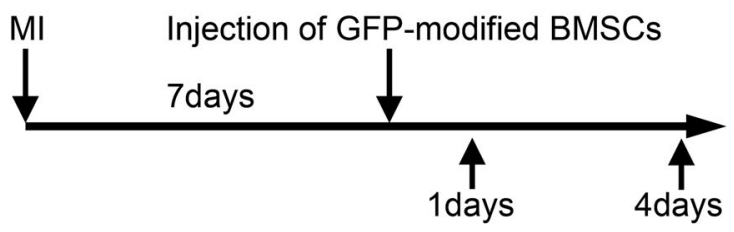

e

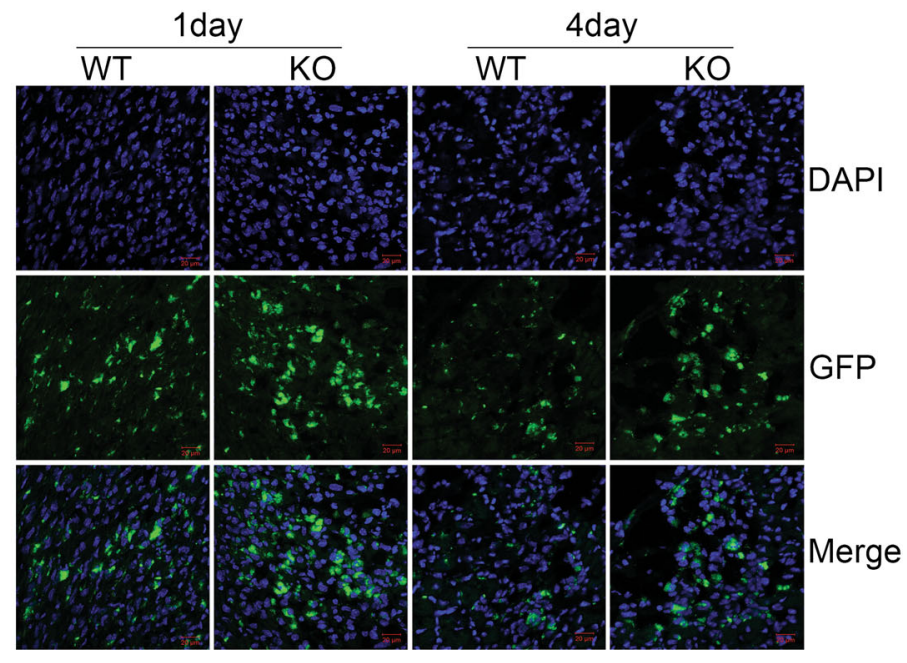

Fig. 6 Effects of transplanted BMSCs survival for treating myocardial infarction in Rab27a KO mice. a Diagram of BMSCs therapy for myocardial infarction in vivo. After left anterior descending artery ligation, male mouse BMSCs were injected into 4 spots of border zone surrounding the infarcted zone of the female mouse heart. $\mathbf{b}$ Schematic depiction of BMSC transplantation and sample collection. $\mathbf{c}$, $\mathbf{d}$ Real-time polymerase chain reaction analyzed Sry gene and GFP mRNA after 1 and 4 days of injection of BMSCs. ${ }^{*} p<0.05$ versus $1 \mathrm{~d}$ WT, \#p $<0.05$ versus 4 days WT. All values were expressed as mean $\pm S D, n=5$ for each group. e GFP fluorescence signal intensity (green fluorescence) and DAPI staining (blue fluorescence) of BMSCs in cardiac tissue were measured by confocal laser scanning microscopy. WT wild-type mice, KO Rab27a knockout mice. Scale bar, $20 \mu m$

results indicated that the CMs-derived particles collected in our experiments were exosomes, and that oxidative stress can promote the secretion of exosomes from CMs.

\section{Oxidative stressed cardiac exosomes promote $\mathrm{H}_{2} \mathrm{O}_{2-}$ induced BMSCs apoptosis in vitro}

Exosomes have an important role in mediating cell-tocell communication. In this study, we explored the effect of cardiac exosomes on BMSCs apoptosis under normal culture or oxidative stress condition. As the previous results have shown that the effects of $\mathrm{H}_{2} \mathrm{O}_{2}$-cdM that promote $\mathrm{H}_{2} \mathrm{O}_{2}$-induced BMSCs apoptosis are more obvious than that of group cdM, we collected the conditioned culture medium of $\mathrm{CMs}$ in this condition and differentially ultracentrifuged isolate exosomes. BMSCs were cultured with $10 \%$ exosomes-depleted fetal bovine serum (FBS) DMEM containing three different concentrations of exosomes $\left(1,2,4 \times 10^{9}\right.$ particles per $\left.\mathrm{ml}\right)$ for $24 \mathrm{~h}$ in normal culture. Cell apoptosis was then determined by western blot; significant increase in cleaved caspase-3/caspase- 3 and the decrease in Bcl-2/Bax ratio was observed, which were dependent on the exosomes concentration in normal culture (Fig. $4 \mathrm{a}-\mathrm{c}$ ). In addition, significant decreases in cell viability were observed in Exo1 $(94.7 \pm 3.1 \%)$ and Exo3 $(83.9 \pm 3.4 \%)$ group compared to NC group $(101.3 \pm 33.3 \%)(p<0.05)$ (Fig. 4g).

To further explore the effect of cardiac exosomes on BMSCs apoptosis under oxidative stress condition, BMSCs were pre-incubated with $10 \%$ exosomes-depleted FBS DMEM with three different concentrations of cardiac exosomes for $24 \mathrm{~h}$, and then treated with serum-free DMEM or exosomes-depleted conditioned medium (D-Ex) and with $500 \mu \mathrm{M} \mathrm{H} \mathrm{H}_{2} \mathrm{O}_{2}$ for additional 24h. Subsequently, cell apoptosis was analyzed by western blot and Flow cytometry. A significant increase in cleaved caspase-3/caspase- 3 and significantly decrease in Bcl-2/ 
Bax ratio was found in D-Ex and Exos group; the level of cleaved caspase-3/caspase-3 was significantly increased and $\mathrm{Bcl}-2 / \mathrm{Bax}$ ratio was significantly decreased in Exos group compared with D-Ex (with the increased concentration of exosomes) (Fig. $4 \mathrm{~d}-\mathrm{f}$ ). In addition, the cell viability in the Exo1 and Exo3 group decreased compared to $\mathrm{H}_{2} \mathrm{O}_{2}$ group $(67.82 \%$ and $57.02 \%$ versus 73.23\%, respectively) (Fig. 4h). Moreover, significantly increased cell apoptosis was found in the Exo1 group (30.79\%) compared with the $\mathrm{H}_{2} \mathrm{O}_{2}$ group (17.31\%) and D-Ex group (23.62\%) (Fig. 4i, j). To sum up, these results suggested that oxidative stressed cardiac exosomes can promote BMSCs apoptosis.

\section{The identification of Rab27a KO mouse and the ability of exosomes secretion}

In order to explore the role of cardiac exosomes in transplanted BMSCs in vivo, we constructed Rab27a KO mice model by designing and synthesizing highly active transcription activator-like effector nuclease (TALEN) specific to Rab27a exon 2 in the mouse genome (Fig. 5b), using a TALEN genome-editing technology. Rab27a, a member of Rab family of small GTPases, has a critical role in secretion of exosomes ${ }^{15}$. Previous studies have shown that Rab27a regulates melanosome transport in melanocytes. Dysfunction in this process has been proposed to cause type 2 Griscelli syndrome, a disease characterized by silvery hair ${ }^{18}$, which was also confirmed by our experiment (Fig. 5a), The Rab27a KO mouse had gray coat color compared to wild-type mouse. Rab27a knockout mice was confirmed by western blot; the level of Rab27a protein in cardiac tissues of Rab27a KO mice was notably downregulated compared to WT mice $(p<0.05)$ (Fig. 5c, d).

Consequently, several assays were performed to determine whether the exosomes released from cardiac cells of Rab27a KO mice were reduced. First, NTA was used to define the number of particles released from cardiac tissue and CMs. The exosomes were purified from the culture of CMs and cardiac tissues and then isolated using the previously described differential centrifugation protocols. NTA showed that the number of the secretory exosomes greatly decreased in $\mathrm{KO} \mathrm{CMs}$ $(44.7 \pm 17.5 /$ cell $)$ compared to WT $(160.3 \pm 42.6 /$ cell $)$, and in $\mathrm{KO}$ cardiac tissues $\left((1.713 \pm 0.320) \times 10^{8} / \mathrm{mg}\right)$ compared to WT $\left((2.941 \pm 0.525) \times 10^{8} / \mathrm{mg}\right)$ (Fig. 5e, f). Secondly, TEM was used to observe the morphology of the exosomes directly. The particles exhibited round-shaped vesicles and diameter $<100 \mathrm{~nm}$, and the exosomes within the $\mathrm{KO} 1$ and $\mathrm{KO} 2$ cell cytoplasm were significantly increased compared to WT1 and WT2 group (the black arrows point), respectively (Fig. 5g), which suggested that exosomes released from Rab27a KO cells were reduced.
The transplanted BMSCs survival for the therapy of $\mathrm{MI}$ in Rab27a KO mice were increased

To further validate the role of cardiac exosomes on the transplanted BMSCs survival in vivo, we transplanted $2.0 \times 10^{6}$ male mouse GFP-modified BMSCs into the viable myocardium bordering the infarction in Rab27a $\mathrm{KO}$ and wild-type female mice (Fig. 6a, b). RT-PCR for mice Y-chromosome Sry DNA and GFP mRNA were used to estimate the survival of implanted cells. Our results showed that the transplanted BMSCs survival increased in Rab27a KO mice by the higher level of Y-chromosome Sry DNA and GFP mRNA, with approximately three-fold enhancement by day 1 and day 4 post cell transplantation $(n=5, p<0.05)$ (Fig. 6c, d). We also used confocal laser scanning microscopy to analyze the GFP fluorescence signal intensity of transplanted cells in heart tissues. The results were consistent with the results of real-time PCR; stronger GFP signal was found in KO group compared to WT group at day 1 and day 4, respectively (Fig. 6e). These data indicated that the transplanted BMSCs survival in infarcted heart was increased in Rab27a KO mice, suggesting that cardiac exosomes may accelerate transplanted BMSCs injury after MI.

\section{Discussion}

There are 1,000 million CMs lost during MI, while typical dose of transplanted cells can reach or even exceed this number. However, only few of the cells may successfully engraft into the myocardium, and are much less likely to continuously survive after transplantation ${ }^{19,20}$. Much of this attrition can be attributed to the harsh microenvironment in and near the region of the infarct; nonetheless the exact mechanism is still not fully understood $^{21}$. To explore whether the injured CMs have an ability to affect the survival of transplanted cells by paracrine action, we cultured BMSCs with CMs conditioned medium under oxidative stress in vitro. Western blot revealed that the expression of apoptosis-related proteins was significantly increased and cell viability was decreased in group cdM and group $\mathrm{H}_{2} \mathrm{O}_{2}$-cdM compared to their respective control. Also, the cell injury in group $\mathrm{H}_{2} \mathrm{O}_{2}$-cdM was more worse compared to group cdM. These findings demonstrated that $\mathrm{CMs}$ conditioned medium could promote $\mathrm{H}_{2} \mathrm{O}_{2}$-induced BMSCs apoptosis; group $\mathrm{H}_{2} \mathrm{O}_{2}$-cdM showed more obvious effects compared to group cdM. Accordingly, we explored what substances in the group $\mathrm{H}_{2} \mathrm{O}_{2}$-cdM take effects.

Cellular cross-talk has a central role for adaptive response of organisms to stress and maintain homeostasis $^{22}$. Direct contact and secreted molecules, including cytokines, growth factors, and secreted exosomes, are two major manners for cellular interaction ${ }^{23}$. Recently, studies have found that exosomes produced by $\mathrm{CMs}$ regulate endothelial cell (EC), cardiac fibroblast, and neighboring 
$\mathrm{CMs}^{24-26}$. We explored whether oxidative stressed cardiac exosomes have effect on BMSCs apoptosis under normal culture or oxidative stress. Apoptosis is an automatic and programmed process mediated by the intracellular proteolytic cascade, which includes the extrinsic pathway and the intrinsic (or mitochondrial) pathway. The two types of caspases are initiator caspases (such as caspase-8 and 9) and executioner caspases (caspase-3, 6, and 7). Activated initiator caspases cleave executioner caspases (such as caspases-3 to cleaved caspase-3, the active form of caspase-3), which execute apoptosis ${ }^{27,28}$. Activation of the intrinsic pathway is mainly mediated by the Bcl-2 family, among which the pro- and anti-apoptotic molecules (Bax and Bcl-2) are the most common markers for apoptosis ${ }^{29}$. The obtained results showed that the expression of apoptosis-related proteins and apoptotic rates were greatly increased in group D-Ex and Exos, while the increased levels were significantly higher in group Exos (with the increased concentration of exosomes). This suggested that the exosomes in oxidative stressed CMs conditioned medium may have an important role in promoting $\mathrm{H}_{2} \mathrm{O}_{2}$-induced BMSCs apoptosis.

There are various cell types in the heart: CMs, fibroblasts, CPCs, ECs, and vascular smooth muscle cells (VSMCs). Several studies have demonstrated that CMs, ECs, fibroblasts, and CPCs can produce and secret exosomes so as to regulate the function of heart in specific condition $^{30-33}$. Secreted exosomes can transport nucleic acids, lipids, and proteins via interstitial fluid and circulating blood, and thus can be involved in local and remote intercellular communication $^{34,35}$. Since we already showed that oxidative stressed cardiac exosomes promote $\mathrm{H}_{2} \mathrm{O}_{2}$-induced BMSCs apoptosis, we wanted to further elucidate whether exosomes secreted from cardiac fibroblasts, ECs, or VSMCs work in the same way.

Cardiomycytes did not act as typical secretory cells. However, in 2007, Gupta and Knowlton ${ }^{36}$ were first who isolated exosomes released from adult rat CMs by using differential ultracentrifugation techniques. To gain insight into the function of exosomes, the exosome proteomics of cardiac cells were also analyzed ${ }^{37}$. In contrast to other EVs, cardiac EVs have a specific signature of the proteome, which highlights its origins in the heart muscle. Moreover, the inducible secretion of exosomes protein is regulated by pathological changes in the environment, including fever, hypoxia, and oxidative stress. Unlike Hsp70 and Hsp90, the heat shock protein 60 (Hsp60) contained in the cardiac EVs has not been previously found in other cell types derived EVs. It has been suggested that extracellular HSP60, when not in exosomes, may trigger cardiomyocyte apoptosis and inflammation through a Toll-like receptor (TLR)-mediated mechanism $^{38,39}$. Tumor necrosis factor- $\alpha$ (TNF- $\alpha$ ) is a cytokine that regulates multiple biological processes in human. TNF- $\alpha$ is released soon after myocardial ischemic injury, and it contributes to myocardial injury and dysfunction ${ }^{40}$. Under hypoxia, CMs are induced by hypoxia inducible factor $1 \alpha$ (HIF- $1 \alpha)$ to generate more TNF- $\alpha$, which are encapsulated by exosomes and then released. Incubating these TNF- $\alpha$ containing vesicles with CMs increases apoptosis in $\mathrm{CMs}^{41}$. These studies have shown that $\mathrm{CMs}$ have the ability to transport protein to other cells by generating and secreting exosomes so as to regulate cell survival or apoptosis. These findings instigated us to further explore the mechanism underlying cardiac exosomes-accelerated transplanted BMSCs injury.

In conclusion, this study demonstrated that cardiac exosomes accelerate transplanted BMSCs injury in infarcted heart, revealing a previously unrecognized mechanism underlying the poor survival of transplanted cells. Moreover, blocking the release of cardiac exosomes or its detrimental contents could be used as an effective strategy to enhance implanted BMSCs survival after MI.

\section{Materials and Methods \\ Materials}

Hydrogen peroxide $\left(\mathrm{H}_{2} \mathrm{O}_{2}\right)$ was manufactured by Sigma-Adrich Inc. (St. Louis, MO, USA). Antibodies raised against $\beta$-actin, Bax, cleaved caspase-3, caspase-3, Tsg101, HSP70, and GAPDH were obtained from Cell Signaling Technology (Beverly, MA, USA) and anti-Bcl-2, CD63 were purchased from Bioworld Technology, Inc. (USA). Enhanced chemiluminescence (ECL) kit was provided by Santa Cruz Biotechnology Inc.

\section{Animals}

Animals were raised and treated in accordance with the Guangdong Animal Center for the ethical treatment of animals. We claim that the animal experiments in this study were approved by the Institutional Animal Care and Use Committee of Guangzhou Medical University (Guangzhou, China). A total of $160-180 \mathrm{~g}$ adult male Sprague-Dawley rats and 15-18 g C57BL/6 mice were obtained from Guangdong Laboratory Animal Monitoring Institute. During the study, the animals had access to standard laboratory diet and drinking water adlibitum.

\section{Purification of BMSCs and neonatal rat CMs}

Primary isolation of rat and male mouse BMSCs were performed according to previously established methods ${ }^{42}$. The BMSCs were cultured with DMEM (Gibco) containing 10\% (FBS) and antibiotics (Gibco). Culture medium was replaced every 3 days and the removal of nonadherent hematopoietic cells was performed. Passage 3 BMSCs were used for further experiments.

Isolation of neonatal rat CMs was performed as previously described ${ }^{43}$. Briefly, left ventricles from 1 to 2 -day 
old rats were collected and sliced into small pieces, and then digested with collagenase Type II (Gibco) at $37^{\circ} \mathrm{C}$. After digestion, the cells were resuspended in DMEM containing $10 \%$ FBS. Then, differential preplating was performed to enrich CMs, which were seeded in 10\%FBS DMEM containing $0.1 \mathrm{mM}$ bromodeoxyuridine (BrdU). Culture media were changed after $48 \mathrm{~h}$ incubation and the cells were used for further experiments.

\section{In vitro model of oxidative stress injury}

To mimic the oxidative stress microenvironment after MI that the CMs or transplanted BMSCs encounter in vivo, the cells were exposed to different concentrations of hydrogen peroxide $\left(\mathrm{H}_{2} \mathrm{O}_{2}\right)$ in serum-free DMEM (Gibco) for $24 \mathrm{~h}$. The cell viability was detected by the Cell Counting kit-8 (CCK-8; Dojindo Laboratories) according to the manufacturer's instructions. For the detection of the cleaved caspase- 3 and caspase- 3 , protein lysates were prepared and detected by western blot analysis.

\section{In vitro experiments with conditioned medium}

Conditioned medium was prepared as follows: $80-90 \%$ confluent CMs were cultured with serum-free DMEM (cdM) or serum-free DMEM and subjected to $100 \mu \mathrm{M}$ $\mathrm{H}_{2} \mathrm{O}_{2}$ treatment $\left(\mathrm{H}_{2} \mathrm{O}_{2}\right.$-cdM) for $24 \mathrm{~h}$. Ctr-cdM (without $\mathrm{CMs}$ ) and $\mathrm{Ctr}-\mathrm{H}_{2} \mathrm{O}_{2}$-cdM (without CMs) served as control of cdM and $\mathrm{H}_{2} \mathrm{O}_{2}$-cdM, respectively. The collected culture supernatant was centrifuged at $1,500 \mathrm{rpm}$ for 10 min, and was used immediately or after being stored at $-20^{\circ} \mathrm{C}$. After the $80-90 \%$ confluence, BMSCs were cultured with controlled medium (Ctr-cdM and $\mathrm{Ctr}-\mathrm{H}_{2} \mathrm{O}_{2-}$ cdM) or conditioned medium (cdM and $\mathrm{H}_{2} \mathrm{O}_{2}-\mathrm{cdM}$ ) and then mixed with or without $500 \mu \mathrm{M} \mathrm{H}_{2} \mathrm{O}_{2}$ for $24 \mathrm{~h}$. Cell viability analysis was detected using CCK-8. Cell apoptosis was determined by western blot.

\section{Isolation and characterization of exosomes}

The cardiac exosomes isolation procedures were performed by differential ultracentrifugation ${ }^{44}$. Briefly, $50 \mathrm{ml}$ serum-free DMEM was used for culturing CMs in two T175 flasks. After treatment with $100 \mu \mathrm{M} \mathrm{H}_{2} \mathrm{O}_{2}$ for $24 \mathrm{~h}$, supernatant was differentially centrifuged at $300 \mathrm{x} g$ for 10 min, 2000x $g$ for $10 \mathrm{~min}$ and $10,000 \mathrm{x} g$ for $60 \mathrm{~min}$ to remove any residual cells and debris, then centrifuged at $120,000 \mathrm{x} g$ for $90 \mathrm{~min}$ at $4^{\circ} \mathrm{C}$ to precipitate exosomes. The medium that removed exosomes after centrifugation served as exosomes-depleted conditioned medium (D-Ex) for culturing with BMSCs. The isolated exosomal precipitates were washed once with cold sterile phosphatebuffered saline (PBS), then suspended in $50 \mu$ of PBS or dissolved in lysis buffer for protein extraction.

The concentration and size distribution of exosomes were confirmed by NTA using NanoSight NS300 (Malvern, UK). The differences in exosome concentrations between conditioned medium from CMs mixed with or without $100 \mu \mathrm{M} \mathrm{H}_{2} \mathrm{O}_{2}$ for $24 \mathrm{~h}$ were recorded. Three recordings were performed for each sample. Western blot was used to detect the exosomal protein markers (CD63, HSP70, and Tsg101).

For the Transmission Electron Microscopy (TEM) morphology observation, $3 \mu$ of exosome suspension was absorbed onto formvar carbon-coated copper electron microscopy grids (200 mesh) at room temperature for 5 min, and then subjected to $2 \%$ uranyl acetate staining for an additional minute. Grids were washed three times with PBS and were maintained in semi-dry state before observation by TEM (Hitachi H7650 TEM, Japan).

\section{Exosome Uptake assays}

The PKH67 green fluorescent cell linker kit was used for labeling exosomes according to the manufacturer's instructions (Sigma Aldrich). Briefly, exosomes resuspended in buffer were mixed with $\mathrm{PKH}$ dyes at room temperature for $5 \mathrm{~min}$. Consequently, the pellets were added to PBS containing $5 \%$ bovine serum albumin (BSA) and subjected to ultracentrifugation at 120,000 $\mathrm{x}$ for $90 \mathrm{~min}$ to remove free dye. The samples were then resuspended in $50 \mu \mathrm{l}$ DMEM containing 10\% exosomes-depleted FBS. Labeled exosomes were cultured with BMSCs for $24 \mathrm{~h}$. Finally, exosome-PKH67-treated BMSCs were fixed and stained with rhodaminephalloidin and DAPI, and evaluated by fluorescence microscopy.

\section{BMSCs cultured with oxidative stressed cardiac exosomes}

BMSCs were cultured with three different concentrations of exosomes $\left(1,2,4 \times 10^{9}\right.$ particles per ml) for $24 \mathrm{~h}$ in normal culture (DMEM containing 10\% exosomesdepleted FBS). In exploring the effects of cardiac exosomes on BMSCs apoptosis under oxidative stress, BMSCs were pre-incubated with three different concentrations of exosomes (as previous described) for $24 \mathrm{~h}$, and then treated with serum-free DMEM and $500 \mu \mathrm{M}$ $\mathrm{H}_{2} \mathrm{O}_{2}$ for $24 \mathrm{~h}$. Following treatment, western blot, and Flow cytometry with Annexin V-FITC/PI kit (eBioscience) were used to analyze the cell apoptosis, while CCK- 8 assay was used to assess cell viability.

\section{Cell apoptosis analysis by Flow cytometry}

Cell apoptosis was analyzed using Annexin V-FITC Apoptosis Detection Kit (eBioscience), following the manufacturer's instructions. Briefly, the cells were collected and washed with PBS and then resuspended in $200 \mu \mathrm{l}$ binding buffer. Consequently, cells were mixed with $5 \mu \mathrm{l}$ Annexin V-FITC at room temperature for $10 \mathrm{~min}$ following the incubation with 10 ul propidiumlodide (PI). Finally, early and late apoptosis were analyzed using FACS cytometry (BD FACSVerse). 


\section{Western blot}

Western blot analysis was performed as previously described $^{45}$. Briefly, proteins were collected, normalized, and separated by $12 \%$ SDS-PAGE and electrotransferred to methanol-treated polyvinylidene difluoride (PVDF) membranes. 5\% nonfat milk in TBST for $1 \mathrm{~h}$ at room temperature was used to block the membranes. The membranes were then incubated with antibodies overnight at $4{ }^{\circ} \mathrm{C}$, followed by HRP linked secondary antibody. The detection was performed by the ECL system.

\section{Constructing Rab27a KO mice model by a TALEN genome- editing technique}

TALENs are a combination of the FokI endonuclease and the TAL effector DNA-binding domain, which can be engineered to cut specific sequences of $\mathrm{DNA}^{46}$. For constructing Rab27a KO mice model, we designed and synthesized highly active TALEN specific to exon 2 of Rab27a. The engineered restriction enzymes were then introduced into cells, for genome editing of Rab27a in situ. Coat color phenotype and the protein expression of Rab27a were analyzed to identify Rab27a KO mice.

\section{The identification of the ability of exosomes secretion in Rab27a KO mouse}

The exosomes released from neonatal mouse CMs were isolated using the same method as for rat CMs. The exosomes released from cardiac tissue were isolated using a previously described method ${ }^{47}$. Briefly, the heart homogenate was sequentially filtered through a $40 \mu \mathrm{m}$ mesh filter (BD) and a $0.2 \mu \mathrm{m}$ syringe filter (Thermo). The filtrate was then condensed through a $100 \mathrm{kD}$ ultrafiltration centrifuge tube (Amicon ultra 15; Millipore). The exosomes from the condensed filtrates were isolated using the differential ultracentrifugation protocols. The concentrations of cardiac exosomes were confirmed by NTA, and TEM micrograph was used for analyzing exosomes distribution in cardiac tissues.

\section{Induction of $\mathrm{MI}$ and BMSCs Transplantation}

A MI model was constructed in female mice (20-23 g). Briefly, under spontaneous isoflurane inhalation induced anesthesia, the animals underwent tracheal intubation via oral cavity and were mechanically ventilated with room air supplemented with oxygen using a rodent ventilator (ALCBIO-V8S). The heart was exposed by left-side thoracotomy and the left anterior descending artery (LAD) was ligated $2 \mathrm{~mm}$ from its origin between the pulmonary artery conus and the left atrium using 9-0 polyester suture. Successful infarction was confirmed by the blanching of the left ventricular muscle and an ST elevation on electrocardiograms.

Passage 3 male mouse BMSCs were transduced with an adenoviral vector encoding the GFP reporter gene (vigene). Transduction efficiency was evaluated by detection of GFP fluorescence signal intensity. GFPmodified BMSCs were detached with $0.125 \%(\mathrm{w} / \mathrm{v})$ trypsin, suspended in PBS, and kept on ice until injection. Seven days after coronary ligation, the surviving mice received re-thoracotomy and an intramyocardial injection of $2.0 \times 10^{6}$ cells (total of $50 \mathrm{ul}$ in PBS) with a 30-gauge needle; the injection was performed at four sites into anterior and lateral aspects of the viable myocardium bordering the infarction. Two groups (20 mice/group) were used in this study, including wild-type mice (WT) and Rab27a KO mice (KO). Each group was then divided into two additional subgroups (10 mice/group). One group was subjected to real-time PCR for determining the survival rate after 1and 4 days of cell transplantation. The other group underwent for confocal laser scanning microscopy analysis.

\section{Real-Time PCR for implanted BMSCs Survival}

The mouse heart samples from different groups were electrically-driven tissue homogenated and the genomic DNA and total RNA were isolated using TRIzol Reagent (Invitrogen). The concentration and purity of the DNA or RNA were measured by spectrophotometry. GFP-cDNA was reverse-transcripted using ReverTra Ace qPCR RT Kit (TOYOBO). Real-Time PCR was performed for quantification of the Sry-DNA and GFP-cDNA of heart tissues after 1- and 4-days of cell implantation with THUNDERBIRD SYBR qPCR MiX Kit (TOYOBO).The primer sequences for amplification of GFP, mouse Ychromosome Sry, and $\beta$-actin genes are listed below: GFP: sense, 5'-AAGTTCATCTGCACCACCG-3'; antisense, 5'-TCCTTGAAGAAAGGTGCG-3'; Sry: sense, 5' CTGCTGTGAACAGACACTAC-3'; antisense, $5^{\prime}$ GACTCCTCTGACTTCACTTG-3'; $\beta$-actin: sense, $5^{\prime}$ TGGCTCCTAGCACCATGAAG-3'; and antisense, $5^{\prime}$ AACGCAGCTCAGTAACAGTCC- $3{ }^{\prime}$. The cycling conditions were set at $2 \mathrm{~min}$ at $95^{\circ} \mathrm{C}$ for initial prenaturation, 40 cycles of denaturation at $95^{\circ} \mathrm{C}$ for $5 \mathrm{~s}$, annealing at $60^{\circ} \mathrm{C}$ for $15 \mathrm{~s}$, and extension at $72{ }^{\circ} \mathrm{C}$ for $60 \mathrm{~s}$. The PCR-amplified DNA was quantified and the results were normalized against $\beta$-actin expression. The relative PCR products were calculated with the $2^{-\Delta \Delta \mathrm{Ct}}$ method.

\section{Confocal laser scanning microscopy}

For detecting the survival rate of transplanted BMSCs, the GFP fluorescence signal intensity of transplanted cells in heart tissues were examined with confocal laser scanning microscopy as previously described ${ }^{48,49}$. Briefly, heart tissues after 1- and 4- days of cell implantation were made into frozen sections, then fixed in $3.7 \%$ buffered paraformaldehyde for $10 \mathrm{~min}$. Staining of 40, 6-diamino-2phenylindole (DAPI) (sigma-Aldrich) indicated the nucleus. Finally, the GFP fluorescence signal intensity of 
transplanted cells in heart tissues was examined with confocal laser scanning microscopy.

\section{Statistical analyses}

Data in this study are expressed as the means \pm standard deviation (SD). Differences were compared by analysis of variance (ANOVA) or $t$-test, as appropriate. A value of $p$ $<0.05$ was considered statistically significant. SPSS 13.0 was used to analyze the data.

\section{Acknowledgements}

The study was supported in part by the National Natural Science Foundation of China $(81570259,81400231)$, the Natural Science Foundation of Guangdong Province (2017A030313796), the Science and Technology Planning Project of Guangdong Province (2014A020212330), The education features innovative project of Guangdong Province (2016KTSCX118), The Key Medical Disciplines and Specialties Program of Guangzhou (2017-2019), Pearl River S\&T Nova Program of Guangzhou (No. 201506010071), and General Project (1201610098) from Guangzhou Education Commission.

\section{Conflict of interest}

The authors declare that they have no conflict of interest.

\section{Publisher's note}

Springer Nature remains neutral with regard to jurisdictional claims in published maps and institutional affiliations.

Received: 8 November 2017 Revised: 8 February 2018 Accepted: 9 February 2018

Published online: 02 March 2018

\section{References}

1. Herrmann, J. L. et al. Cell-based therapy for ischemic heart disease: a clinical update. Ann. Thorac. Surg. 88, 1714-1722 (2009).

2. Wu, K. Han, Z., Mo, X. \& Zhou, B. Cell delivery in cardiac regenerative therapy. Ageing Res. Rev. 11, 32-40 (2012).

3. Liang, X. et al. Activation of NRG1-ERBB4 signaling potentiates mesenchymal stem cell-mediated myocardial repairs following myocardial infarction. Cell Death Dis. 6, e1765 (2015).

4. Cai, M. et al. Bone marrow mesenchymal stem cells (BM-MSCS) improve heart function in swine myocardial infarction model through paracrine effects. Sci. Rep. 6, 28250 (2016).

5. Cao, F. et al. In vivo visualization of embryonic stem cell survival, proliferation, and migration after cardiac delivery. Circulation 113, 1005-1014 (2006).

6. Zhang, S. et al. HIF-2a and Oct4 have synergistic effects on survival and myocardial repair of very small embryonic-like mesenchymal stem cells in infarcted hearts. Cell Death Dis. 8, e2548 (2017).

7. Mangi, A. A. et al. Mesenchymal stem cells modified with Akt prevent remodeling and restore performance of infarcted hearts. Nat. Med. 9, 1195-1201 (2003).

8. Chang, W. et al. Mesenchymal stem cells pretreated with delivered Hph-1Hsp70 protein are protected from hypoxia-mediated cell death and rescue heart functions from myocardial injury. Stem Cells 27, 2283-2292 (2009).

9. Zhang, Z. et al. Autophagy mediates the beneficial effect of hypoxic preconditioning on bone marrow mesenchymal stem cells for the therapy of myocardial infarction. Stem Cell Res. Ther. 8, 89 (2017).

10. Don, C. W. \& Murry, C. E. Improving survival and efficacy of pluripotent stem cell-derived cardiac grafts. J. Cell Mol. Med. 17, 1355-1362 (2013).

11. Gitler, A. D., Lu, M., Jiang, Y., Epstein, J. A. \& Gruber, P. J. Molecular markers of cardiac endocardial cushion development. Dev. Dyn. 228, 643-650 (2003).

12. Sluijter, J. P., Verhage, V., Deddens, J. C., van den Akker, F. \& Doevendans, P. A. Microvesicles and exosomes for intracardiac communication. Cardiovasc. Res. 102, 302-311 (2014)

13. Yanez-Mo, M. et al. Biological properties of extracellular vesicles and their physiological functions. J. Extracell. Vesicles 4, 27066 (2015).
14. Kishore, R. \& Khan, M. More than tiny sacks: stem cell exosomes as cell-free modality for cardiac repair. Circ. Res. 118, 330-343 (2016).

15. Ostrowski, M. et al. Rab27a and Rab27b control different steps of the exosome secretion pathway. Nat. Cell Biol. 12, 19-30 (2010).

16. Pfeffer, S. R. Two Rabs for exosome release. Nat. Cell Biol. 12, 3-4 (2010).

17. Cosme, J., Liu, P. \& Gramolini, A. O. The cardiovascular exosome: current perspectives and potential. Proteomics 13, 1654-1659 (2013).

18. Ishida, M., Arai, S. P., Ohbayashi, N. \& Fukuda, M. The GTPase-deficient Rab27A (Q78L) mutant inhibits melanosome transport in melanocytes through trapping of Rab27A effector protein Slac2-a/melanophilin in their cytosol: development of a novel melanosome-targetinG tag. J. Biol. Chem. 289 11059-11067 (2014).

19. Zeng, L. et al. Bioenergetic and functional consequences of bone marrowderived multipotent progenitor cell transplantation in hearts with postinfarction left ventricular remodeling. Circulation 115, 1866-1875 (2007).

20. Guo, Y. et al. Repeated doses of cardiac mesenchymal cells are therapeutically superior to a single dose in mice with old myocardial infarction. Basic Res. Cardiol. 112, 18 (2017).

21. Haider, H. \& Ashraf, M. Strategies to promote donor cell survival: combining preconditioning approach with stem cell transplantation. J. Mol. Cell Cardiol. 45, 554-566 (2008).

22. Chistiakov, D. A., Orekhov, A. N. \& Bobryshev, Y. V. Cardiac extracellular vesicles in normal and infarcted heart. Int. J. Mol. Sci. 17, 63 (2016).

23. Cenvio, E., Barile, L., Moccetti, T. \& Vassalli, G. Exosomes for intramyocardial intercellular communication. Stem Cells Int. 2015, 482171 (2015).

24. Waldenstrom, A., Genneback, N., Hellman, U. \& Ronquist, G. Cardiomyocyte microvesicles contain DNARRNA and convey biological messages to target cells. PLoS ONE 7, e34653 (2012).

25. Wang, X. et al. Cardiomyocytes mediate anti-angiogenesis in type 2 diabetic rats through the exosomal transfer of miR-320 into endothelial cells. J. Mol. Cell Cardiol. 74, 139-150 (2014).

26. Yang, Y. et al. Exosomal transfer of miR-30a between cardiomyocytes regulates autophagy after hypoxia. J. Mol. Med. 94, 711-724 (2016).

27. Huang, H. et al. Two clinical drugs deubiquitinase inhibitor auranofin and aldehyde dehydrogenase inhibitor disulfiram trigger synergistic anti-tumor effects in vitro and in vivo. Oncotarget 7, 2796-2808 (2016).

28. Morris, G., Walker, A. J., Berk, M., Maes, M. \& Puri, B. K. Cell Death Pathways: a Novel Therapeutic Approach for Neuroscientists. Mol. Neurobiol. doi: 10.1007/ s12035-017-0793-y. Epub ahead of print(2017).

29. Liu, N. et al. Calcium channel blocker verapamil accelerates gambogic acidinduced cytotoxicity via enhancing proteasome inhibition and ROS generation. Toxicol. In Vitro 28, 419-425 (2014).

30. Zhang, S. et al. HIF-2alpha and Oct4 have synergistic effects on survival and myocardial repair of very small embryonic-like mesenchymal stem cells in infarcted hearts. Cell Death Dis. 8, e2548 (2017).

31. Bang, C. et al. Cardiac fibroblast-derived microRNA passenger strand-enriched exosomes mediate cardiomyocyte hypertrophy. J. Clin. Invest. 124, 2136-2146 (2014).

32. Kervadec, A. et al. Cardiovascular progenitor-derived extracellular vesicles recapitulate the beneficial effects of their parent cells in the treatment of chronic heart failure. J. Heart Lung Transplant. 35, 795-807 (2016),

33. Halkein, J. et al. MicroRNA-146a is a therapeutic target and biomarker for peripartum cardiomyopathy. J. Clin. Invest. 123, 2143-2154 (2013).

34. Valadi, H. et al. Exosome-mediated transfer of mRNAs and microRNAs is a novel mechanism of genetic exchange between cells. Nat. Cell Biol. 9, 654-659 (2007).

35. Peinado, H. et al. Melanoma exosomes educate bone marrow progenitor cells toward a pro-metastatic phenotype through MET. Nat. Med. 18, 883-891 (2012).

36. Gupta, S. \& Knowlton, A. A. HSP60 trafficking in adult cardiac myocytes: role of the exosomal pathway. Am. J. Physiol. Heart Circ. Physiol. 292, H3052-H3056 (2007).

37. Malik, Z. A. et al. Cardiac myocyte exosomes: stability, HSP60, and proteomics. Am. J. Physiol. Heart Circ. Physiol. 304, H954-H965 (2013).

38. Kim, S. C. et al. Extracellular heat shock protein 60 , cardiac myocytes, and apoptosis. Circ. Res. 105, 1186-1195 (2009).

39. Tian, J. et al. Extracellular HSP60 induces inflammation through activating and up-regulating TLRs in cardiomyocytes. Cardiovasc. Res. 98, 391-401 (2013).

40. Li, D. et al. Kinetics of tumor necrosis factor alpha in plasma and the cardioprotective effect of a monoclonal antibody to tumor necrosis factor alpha in acute myocardial infarction. Am. Heart J. 137, 1145-1152 (1999). 
41. Yu, X. et al. Mechanism of TNF-alpha autocrine effects in hypoxic cardiomyocytes: initiated by hypoxia inducible factor 1alpha, presented by exosomes. J. Mol. Cell Cardiol. 53, 848-857 (2012).

42. Zhang, M. et al. Bone marrow mesenchymal stem cell transplantation retards the natural senescence of rat hearts. Stem Cells Transl. Med. 4, 494-502 (2015).

43. Liu, N. et al. Ubiquitin-specific protease 14 regulates cardiac hypertrophy progression by increasing GSK-3beta phosphorylation. Biochem. Biophys. Res. Commun. 478, 1236-1241 (2016).

44. Li, P., Kaslan, M., Lee, S. H., Yao, J. \& Gao, Z. Progress in exosome isolation techniques. Theranostics 7, 789-804 (2017).

45. Liu, N. et al. The combination of proteasome inhibitors bortezomib and gambogic acid triggers synergistic cytotoxicity in vitro but not in vivo. Toxicol. Lett. 224, 333-340 (2014).
46. Boch, J. TALEs of genome targeting. Nat. Biotechnol. 29, 135-136 (2011).

47. Chaturvedi, P., Kalani, A., Medina, I., Familtseva, A. \& Tyagi, S. C. Cardiosome mediated regulation of MMP9 in diabetic heart: role of mir29b and mir455 in exercise. J. Cell Mol. Med. 19, 2153-2161 (2015).

48. Huang, J. et al. miR-34a modulates angiotensin I-induced myocardial hypertrophy by direct inhibition of ATG9A expression and autophagic activity. PLoS ONE 9, e94382 (2014).

49. Liu, N. et al. Ubiquitin-specific protease 14 regulates LPS-induced inflammation by increasing ERK1/2 phosphorylation and NF-kappaB activation. Mol. Cell Biochem. 431, 87-96 (2017). 